\title{
Letrozole for Female Infertility
}

\author{
Ai-Min Yang, Na Cui, Yi-Fei Sun and Gui-Min Hao* \\ Department of Reproductive Medicine, The Second Hospital of Hebei Medical University, Shijiazhuang, China
}

Letrozole, an aromatase inhibitor that blocks estrogen synthesis by inhibiting the final step of the estrogen biosynthetic pathway, has been used in the applications of a wide range of infertility settings. It has been more than 20 years since the initial clinical trial of letrozole for ovulation induction. In light of the accumulating clinical and basic evidence, the efficacy and safety of letrozole have been identified. This mini review focuses on our current knowledge of the applications and mechanisms of letrozole for female infertility and

OPEN ACCESS

Edited by:

Richard Ivell,

University of Nottingham,

United Kingdom

Reviewed by:

Lars Fester,

Friedrich-Alexander-Universität Erlangen-Nürnberg, Germany

Filippo Maffezzoni,

Civil Hospital of Brescia, Italy

*Correspondence:

Gui-Min Hao

haoguimin@163.com

Specialty section:

This article was submitted to

Reproduction,

a section of the journal

Frontiers in Endocrinology

Received: 04 March 2021

Accepted: 01 June 2021

Published: 16 June 2021

Citation:

Yang A-M, Cui N, Sun Y-F and

Hao G-M (2021) Letrozole

for Female Infertility.

Front. Endocrinol. 12:676133.

doi: 10.3389/fendo.2021.676133 various questions are put forward about how letrozole could be more effectively used.

Keywords: letrozole, ovulation induction (OI), frozen-thawed embryo transfer, fertility preservation, endometrium preparation

\section{INTRODUCTION}

In 1986, a new compound was tested by Ciba-Geigy (later Novartis) in an in vivo assay (1). This compound, CGS 20267, now known as letrozole, was a third-generation, nonsteroidal aromatase inhibitor (1). Letyrozole was approved to be effective for a wide range of breast cancer settings, which at present it's only registered indication (2). In 1993, letrozole was initially used in animal ovulation induction (OI) (3). In 2000, the first pilot study for the clinical use of letrozole for OI indicated a high rate of ovulation in polycystic ovary syndrome (PCOS) patients (4). In 2004, a study by Legro et al. in the New England Journal of Medicine showed that letrozole was a more effective medication for OI than clomiphene in women with PCOS. This suggested that letrozole may be a better choice as a first-line medication (5). From then on, the use of letrozole in infertility treatment has been greatly popularized, and the studies about its clinical effects and mechanisms of action continued.

Letrozole is a non-steroidal, highly selective oral aromatase inhibitor (AI), which can reversibly bind to the rate-limiting enzyme P450 aromatase in estrogen biosynthesis pathway and inhibit the conversion of testosterone to estradiol and androstenedione to estrone (6). The down-regulated estrogen increases the secretion of pituitary follicle-stimulating hormone (FSH) as feedback to stimulate ovulation. Nowadays, letrozole has been extensively used to induce ovulation in anovulatory infertility patients and to augment follicles for ovulatory women. Furthermore, letrozole is used as an adjunct for intrauterine insemination (7) and in vitro fertilization (IVF)/ intracytoplasmic sperm injection (ICSI) cycles (8). Letrozole is also used for fertility preservation in women with estrogen-sensitive cancers. Also, studies showed the effectiveness of letrozole in endometrium preparation for frozen-thawed embryo transfer (FET) $(9,10)$. In this mini review, 
we summarize the mechanism basis and clinical effects of letrozole for female infertility and we aim to provide evidence for the application of letrozole for different settings of infertility treatment.

\section{PHARMACOLOGY}

Letrozole's chemical structure is 4,40-[(1H-1,2,4-triazol-1-yl) methylene] bis-benzonitrile (11). It was proven to be a highly potent inhibitor of aromatase in vitro, in vivo in animals, and humans (11). Plasma kinetics of letrozole was characterized by a fast and complete absorption ( $\mathrm{t} \max =1 \mathrm{~h}$ ) (the mean absolute bioavailability is $99.9 \%$ ), and a rather slow elimination, the plasma half-lives of letrozole ( $2.5 \mathrm{mg}$ once daily) are 41 48 hours after oral administration (12). The extent of letrozole absorption was not influenced by the intake of food (13). The major route of elimination is metabolism by CYP450 isoenzymes into an inactive carbinol metabolite (2). The $t / 2$ of letrozole can markedly increase in hepatic impairment patients and caution is required (2).

Letrozole inhibits the aromatase activity by more than $99 \%$, and endogenous estrogen synthesis by $97 \%-99 \%$ (12). The mechanisms of letrozole for OI remain unclear. However, it has been proposed that it may act through both centrally and peripherally mechanisms (14). Centrally, letrozole dramatically lowers the estrogen level, which prevents its negative feedback on the hypothalamic-pituitary-gonad (HPO) axis (15). Peripherally, as the conversion of androgen substrates to estrogen is inhibited, the temporary accumulation of intraovarian androgens may increase follicular sensitivity through amplification of FSH receptor gene expression (15-18). Also, androgens accumulation in the follicle may stimulate insulin-like growth factor 1 (IGF-1) and other endocrine and paracrine factors, which may synergize with FSH to promote folliculogenesis (19). The mechanism of action of letrozole for ovulation induction was shown in Figure 1.

Letrozole may be used alone or in conjunction with exogenous FSH for OI, but the optimal dose and regimen of letrozole is not yet clear (20). The protocol of letrozole for OI mimics the use of clomiphene citrate (CC). Typical treatment of letrozole consists of 2.5 to $7.5 \mathrm{mg}$ daily taken during days $3 \sim 7$ of menstrual for a 5-day course, which coincides with the availability of a $6 \sim 8 \mathrm{~mm}$ follicle. The $6 \mathrm{~mm}$ follicle is equipped with a high level of androgen receptors and increased androgen levels at this time promote granulosa cell mitosis and induction of FSH receptors (21-23).

\section{OVLATION IN INDUCTION FOLLOWED BY TIMED INTERCOURSE OR INTRAUTERINE INSEIMINATION (IUI)}

CC affects the development of endometrial and cervical mucus and often leads to the development of multiple follicles (24). Besides, about $15 \%$ of PCOS patients were CC-resistant who do not respond to CC treatment (25). The mechanism of action of CC for ovulation induction was shown in Figure 1. Because letrozole does not inhibit negative feedback of estrogen to HPO axis, it usually induces single follicle development and avoids multiple pregnancies. On the other
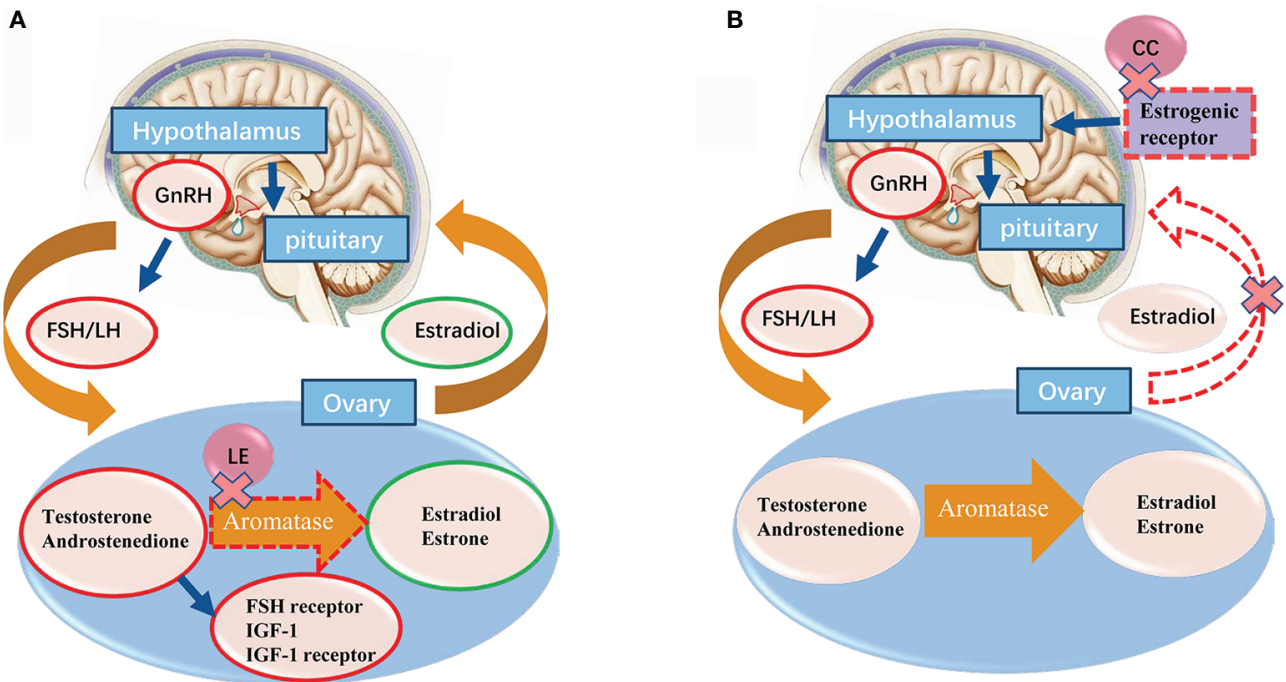

FIGURE 1 | (A) The proposed mechanisms of letrozole for ovarian induction are centrally effect on releasing the pituitary-hypothalamic axis from estrogen negative feedback and locally effect on blocking the conversion of testosterone to estradiol and androstenedione to estrone in ovary. With the concomitant accumulation of androgens inside the ovary, promoting the follicular FSH receptor, IGF-1 and IGF-1 receptor expression, which in turn stimulates follicular growth. Normal central feedback mechanisms remain intact in letrozole ovarian induction protocol. (B) Clomiphene citrate administration induces gonadotropin release by binding to the estrogen receptors (ERs) in the hypothalamus, thereby blocking the negative feedback effect of estradiol. Red circle means increase, green circle means decrease. $\mathrm{GnRH}$, gonadotrophin-releasing hormone; FSH, follicle-stimulating hormone; LH, lutenizing hormone; IGF, insulin-like growth factor; LE, letrozole. 
hand, since letrozole has a relatively short half-life (41 48 hours) (12), estrogen target tissues (such as endometrium and cervical mucus) are potentially spared adverse effects, as suggested by clinical (26) and experimental data (27). Therefore, letrozole has less effect on endometrium thickness and receptivity, and it is more conducive to embryo implantation.

The debates over the merits of letrozole and CC in anovulatory infertility have never stopped. For patients with WHO group II anovulation [WHO group anovulation classification was shown in Table 1 (28)], there is high quality evidence that has proved that letrozole is superior to CC in terms of ovulation rate, pregnancy rate and live birth rate (29-33), but did not differ in terms of the OHSS rate (32), multiple pregnancy (32) and miscarriage rates (30-32). According to the above evidence, the current recommendation is letrozole used as first-line agent for PCOS (34) and other WHO group II anovulation patients (35).

For ovulatory patients, letrozole is also commonly used to increase their chance of becoming pregnant. Typical diagnoses include mild male factor, endometriosis, pelvic factor, and advanced maternal age $(36,37)$. Despite the advantage of letrozole in PCOS patients, letrozole and CC have similar outcomes in infertile women with mild oligoasthenospermia, early-stage endometriosis, and unexplained infertility who underwent time intercourse or intrauterine insemination (IUI) $(38,39)$. An RCT in 2019 showed the combination of letrozole and CC was associated with a higher ovulation rate compared with letrozole alone in women with infertility and PCOS (40). However, further observation is needed on this protocol.

\section{LETROZOLE FOR UNEXPLAINED INFERTILITY}

The diagnosis of unexplained infertility is despite intensive evaluation of both male and female partners, the etiology may

TABLE 1 | World Health Organization (WHO) group anovulation classification (28).

WHO group I Hypogonadotrophic hypogonadism

Idiopathic hypogonadotrophic hypogonadism

Kallmann's syndrome (isolated gonadotrophin deficiency and anosmia)

Functional hypothalamic dysfunction (e. g. excessive weight loss such as in anorexia nervosa, exercise, stress, drugs, iatrogenic)

Pituitary tumour, pituitary infarct (e. g. Sheehan's syndrome)

WHO group II Normogonadotrophic normogonadic ovarian dysfunction Polycystic ovary syndrome

WHO group III Hypergonadotrophic hypogonadism (ovarian failure)

Genetic (e. g. Turner's syndrome)

Autoimmune causes

Infection (e. g. mumps oophoritis)

latrogenic (e. g. surgical menopause, post-radiotherapy or chemotherapy)

Idiopathic

Other endocrinopathies, such as hyperprolactinaemia, thyroid dysfunction, other conditions of androgen excess such as congenital adrenal hyperplasia and androgen-secreting adrenal and ovarian tumours. remain unknown (41). It is identified in 10\%-30\% of couples seeking treatment for infertility (42). A systematic review and meta-analysis in 2019 showed no difference in terms of clinical pregnancy, live birth, spontaneous miscarriage, or twin gestation between letrozole and CC for unexplained infertility (43). A Multicenter randomized controlled trial in 2020, showed that gonadotropin, clomiphene, or letrozole reached the same pregnancy outcomes (44). However, a study by Usama M Fouda et al. indicated that the extended letrozole regimen had a significantly greater pregnancy rate per cycle and cumulative pregnancy rate than $\mathrm{CC}$ in unexplained infertility patients underwent superovulation combined with IUI (42). But the uniform standard use of letrozole for unexplained infertility needs to be incorporated into future studies. Studies have revealed that the levels of endometrial $\alpha v \beta 3$ expression were lower in patients with unexplained infertility than in the fertile control (45). In women with unexplained infertility treated with letrozole, the expression of $\alpha v \beta 3$ integrin, L-selectin, leukemia inhibitory factor (LIF), and pinopod formation in epithelial and stromal was found to be significantly higher as compared to CC (46).

Letrozole would achieve mono-follicular development in most cycles, thereby may reduce multiple gestation pregnancy and OHSS, with a comparable pregnancy success rate with gonadotropins or CC, may become the first choice of treatment for unexplained infertility (41).

\section{CO-ADMINISTRATION OF LETROZOLE DURING CONTROLLED OVARIAN STIMULATION}

Mechanistically, letrozole administration in the early follicular phase during controlled ovarian stimulation (COS) significantly increased the levels of testosterone and androstenedione in follicular fluid (47), which improved follicular sensitivity to FSH stimulation (18). For poor responders, some preliminary reports demonstrated a potential benefit of letrozole for improving ovarian response to FSH and reducing the number of gonadotropin doses but improved pregnancy outcomes $(47-50)$.

For normal/high responders, co-treatment with letrozole significantly lower gonadotropin consumption and reduce the incidence of OHSS, the pregnancy outcomes are similar or higher than the other groups (50-52). Adjunctive use of letrozole may also be an effective means of low-cost IVF therapy particularly in ICSI cycles (8). Also, a study showed co-treatment with letrozole might revert the expression $\alpha v \beta 3$ integrin in endometrium and improve pregnancy outcome (53). In IVM cycles, letrozole priming was not inferior to group receiving low dose FSH in pregnancy rate (54), but very few studies focus on this topic.

In 2017, a review in Cochrane included 3599 participants, found no conclusive evidence indicating that letrozole with or without gonadotropins differed from gonadotropins, either in the general population or in poor responders undergoing IVF 
treatment (55). And the use of letrozole may be associated with a significant increase in the incidence of cycle cancellations, as well as reductions in the mean number of oocytes retrieved (55). High-quality randomized trials are needed to reach a firm conclusion before letrozole adopted into routine clinical COS practice.

\section{LETROZOLE IN THE PREVENTION AND TREATMENT OF OVARIAN HYPERSTIMULATION SYNDROME}

OHSS is a potentially life-threatening complication of ovarian stimulation during the practice of assisted reproductive technologies (ART). In the rat OHSS model, letrozole decreases the level of VEGF, increases the level of PEDF (56), the combined results should lead to a decrease in the incidence of OHSS (57).

A prospective randomized controlled pilot study showed that in PCOS patients with extremely high Anti-Mullerian Hormone $(\mathrm{AMH})$ levels, co-administration with letrozole results in reduced incidence of OHSS (58). However, study from Wang et al. showed that letrozole could significantly decrease the level of serum $\mathrm{E}_{2}$ in patients receiving freeze-all embryo strategy during luteal phase, but letrozole did not significantly reduce the rate of severe OHSS compared with the control group (59). The authors argued that, although the $E_{2}$ level is positively correlated with the occurrence of OHSS, it is still not clear whether the high level of $E_{2}$ is the cause or the result of OHSS. So exogenous AI therapy during the luteal phase cannot completely block OHSS in either pathogenesis or pathophysiology (59). The effectiveness and mechanisms of letrozole in the prevention and treatment of OHSS remains controversial.

\section{LETROZOLE IN PREPARATION OF ENDOMETRIUM FOR FET}

The key to the success of FET is to improve the receptivity of the endometrium and the synchronization of endometrium and embryo development. Although Some studies showed letrozole is superior to natural or hormone-replacement therapy (HRT) in terms of clinical pregnancy, live birth (60) and miscarriage (60, 61). High-quality evidence shows no consistent advantage of any endometrial preparation has been established $(62,63)$. Moreover, A large meta-analysis study with a total of 31 RCTs (5426 women) in 2020 failed to show a definitive optimal protocol for endometrial preparation (64). However, letrozole is cheap, being patient-friendly, yielding at least equivalent pregnancy rates when compared with natural and artificial cycles with or without suppression, require less luteal support than artificial cycles. For anovulatory patients, it may be a better choice than HRT for FET endometrium preparation in term of patient acceptance and cost-effective analysis. More well-controlled clinical studies are needed to provide direct evidence for its advantage in endometrium preparation for FET.

\section{LETROZOLE IN THE TREATMENT OF ENDOMETRIOSIS- ASSOCIATED INFERTILITY}

AIs can suppress the locally produced $\mathrm{E}_{2}$ by endometriotic deposits, this makes letrozole an attractive therapy for endometriosis (65). Few studies focus on using AIs, especially letrozole, to treat endometriosis-associated infertility. In a prospective RCT, letrozole $2.5 \mathrm{mg} /$ day for two months showed no difference with triptorelin and control with regard to the pregnancy rate or the disease-recurrence rate in laparoscopic and histological diagnosis of endometriosis (66). Another RCT showed superovulation with letrozole + IUI versus CC + IUI in stage I-II endometriosis demonstrated no difference in terms of pregnancy rate per cycle and cumulative pregnancy rate (37).

In summary, current evidence about using letrozole in endometriosis-associated infertility patients is limited. The efficiency of letrozole probably varies for different stages of endometriosis. More trials are warranted to provide evidence to guide our clinical management of endometriosis-associated infertility using letrozole.

\section{LETROZOLE FOR FERTILITY PRESERVATION}

With the progress of early diagnosis technology of cancer, the improvement of expected survival time, and the delay of childbearing age, the fertility preservation for young gynecological cancer patients has become an emerging need (67). In the last decades, oocyte and embryo cryopreservation have become standard procedures for fertility preservation (68). However, the standard COS regimen often stimulates the concentration of plasma estradiol and $E_{2}$ to peak as high as 10 times of the natural cycle, which may trigger the recurrence of hormone-sensitive cancers. Compared with the standard COS regimen, letrozole combined with FSH in COS (LE-FSH-COS) significantly decreased plasma $\mathrm{E}_{2}$ peak concentration (69). A systematic review and meta-analysis including 2,121 hormone-sensitive cancer patients, compared the efficacy and safety of COS with letrozole $v$ s. COS without letrozole, it showed the addition of letrozole did not have any negative effect on the number of mature oocytes collected and the other efficacy endpoints (70).

Recently, more and more studies demonstrated the potential beneficial use of letrozole in IVF cycles in breast cancer patients with fertility preservation treatment $(69,71,72)$. Study by Oktay $\mathrm{K}$ et al. about fertility preservation in breast cancer patients further confirmed the effectiveness and safety of the LE-FSHCOS protocol in terms of clinical pregnancy outcomes (73). In this study, the live birth rate of the FET cycle was $45 \%$, and there was no statistical difference between the average live birth rate (38.2\%) of IVF-ET for infertile women of the same age in the United States $(\mathrm{P}=0.2)$. No fetal and neonatal malformation was reported either (73). However, progesterone levels were high and comparable in LE-FSH-COS protocol than conventional 
protocol, since progesterone has been associated with some kinds of tumor cell proliferation, caution is mandatory (71).

The effectiveness of conjunction with letrozole in patients with other hormone-sensitive cancer types has also been supported by several studies. Kawahara et al. proved that letrozole used during ovarian stimulation suppressed the growth of uterine endometrial cancer in a mouse model (74). A pilot study included six obese endometrial cancer patients who wished to preserve their fertility, treatment regimen consisted of $\mathrm{GnRH}$ agonist and letrozole, none of the patients had recurrences after a median follow-up of 4.0 years (range, 1.37.0 years), and pregnancy rate and live birth rate was $50.0 \%$ and $75.0 \%$, respectively (75). The LE-FSH-COS regimen was used in four women with endometrial carcinoma in five IVF cycles. The protocol maintained peak $\mathrm{E}_{2}$ levels close to those of unstimulated cycles, at least in theory, offering a wider safety margin for endometrial cancer patients (34).

Since the effect of COS on ovarian tumors has not been determined, clinical study of LE-FSH-COS in patients with borderline ovarian tumors or invasive tumors is still lacking. Since letrozole can inhibit estrogen levels in the process of COS, theatrically letrozole may help patients with borderline ovarian tumors in reducing the risk of tumor recurrence (76). However, this hypothesis remains to be confirmed by clinical research.

\section{SAFETY}

Initially, there was concern that letrozole for OI may be associated with teratogenic effects on the infants (26). However, subsequent published higher quality researches demonstrated that the rate of overall chromosomal abnormalities, congenital malformation, or adverse pregnancy and neonatal outcomes were not higher in the letrozole group than in the CC group (77-79) and the general population (80). Low-grade hot flashes, arthritis, arthralgia, and myalgia were more frequent in letrozole than placebo group in postmenopausal women with breast cancer after five years of letrozole therapy (2). Though the duration of OI using letrozole is much shorter than breast cancer treatment, study reported the sides effects are headache, hot flashes, abdominal bloating, and abdominal pain including cramps (40). Aromatase is particularly high expressed in temporal and frontal areas of the human brain, these regions are generally associated with learning, memory, sensory processing and dopaminergic activity (81). It is known that letrozole can cross the blood-brain barrier and inhibit the estrogen synthesis of hippocampal and results in cognitive dysfunction and other neurological symptoms (82-84). The study by Rune et al. showed spines, synapses, and synaptic proteins were significantly downregulated in response to letrozole and in siRNA-StAR transfected cells (85). Evidence showed a strong and significant

\section{REFERENCES}

1. Bhatnagar AS. The Early Days of Letrozole. Breast Cancer Res Treat (2007) 105(Suppl 1):3-5. doi: 10.1007/s10549-007-9699-0

2. Goss PE, Ingle JN, Martino S, Robert NJ, Muss HB, Piccart MJ, et al. A Randomized Trial of Letrozole in Postmenopausal Women After Five Years impairment of long-term potentiation (LTP) in female mice as early as six hours after letrozole treatment, and LTP impairment was followed by loss of spine synapses in the hippocampal (86). In clinical, treatment with AI has been reported to be associated with specifically impaired hippocampus-dependent memory (87), mood disturbances, somnolence, anxiety, fatigue, and hot flashes in some studies $(86,88,89)$. Though letrozole is widely used for female infertility nowadays, attention is warrant from doctors and patients about the above side effects.

Letrozole may well be teratogenically safer because its half-life virtually assures elimination from the body before implantation. But before letrozole or CC administration, pregnancy should always be ruled out (90). Further studies are needed to determine optimal dosing and long-term safety for women treated with the drug. In addition, the long-term health effects of letrozole on children need further investigation as well.

\section{CONCLUSIONS}

As a new type of OI drug, the application of letrozole is not only limited to the clinical treatment of OI for timed intercourse but also involves many aspects of infertility treatment. Besides, letrozole is more accessible and has fewer adverse side effects and lower cost than injectable gonadotropins. Its superiority for OI in WHO group II anovulation patients has been confirmed by high-quality clinical and basic studies. The exact mechanism of OI by letrozole is not clear, the clinical applications are still in the experimental stage, and researchers have not yet reached a consensus on the standardized scheme. It is expected that large clinical samples of RCT and mechanism research will provide evidence and clear guidance for clinical application.

\section{AUTHOR CONTRIBUTIONS}

G-MH and A-MY conceived and designed the study. A-MY and NC wrote the manuscript. Y-FS reviewed and edited the manuscript. All authors contributed to the article and approved the submitted version.

\section{FUNDING}

This study was supported by People's Livelihood Science and Technology Project of Hebei Province (20377714D), Natural Science Foundation of Hebei Province (H2019206707 and H2019206674), National key Research and Development program (2018YFC1002104).

of Tamoxifen Therapy for Early-Stage Breast Cancer. N Engl J Med (2003) 349:1793-802. doi: 10.1056/NEJMoa032312

3. Bhatnagar AS, Batzl C, Häusler A, Nogués V. The Role of Estrogen in the Feedback Regulation of Follicle-Stimulating Hormone Secretion in the Female Rat. J Steroid Biochem Mol Biol (1993) 47:161-6. doi: 10.1016/09600760(93)90070-D 
4. Mitwally MFM, Casper RF. Aromatase Inhibition A Novel Method of Ovulation Induction in Women With Polycystic Ovary Syndrome. Reprod Technol (2000) 10:244-7.

5. Legro RS, Brzyski RG, Diamond MP, Coutifaris C, Schlaff WD, Casson P, et al. Letrozole Versus Clomiphene for Infertility in the Polycystic Ovary Syndrome. N Engl J Med (2014) 371:119-29. doi: 10.1056/NEJMoa1313517

6. Rajan RK, Kumar M SS, Balaji B. Soy Isoflavones Exert Beneficial Effects on Letrozole-Induced Rat Polycystic Ovary Syndrome (PCOS) Model Through Anti-Androgenic Mechanism. Pharm Biol (2017) 55:242-51. doi: 10.1080/ 13880209.2016.1258425

7. Huang S, Wang R, Li R, Wang H, Qiao J, Mol BWJ. Ovarian Stimulation in Infertile Women Treated With the Use of Intrauterine Insemination: A Cohort Study From China. Fertil Steril (2018) 109:872-8. doi: 10.1016/ j.fertnstert.2018.01.008

8. Mukherjee S, Sharma S, Chakravarty BN. Letrozole in a Low-Cost In Vitro Fertilization Protocol in Intracytoplasmic Sperm Injection Cycles for Male Factor Infertility: A Randomized Controlled Trial. J Hum Reprod Sci (2012) 5:170-4. doi: 10.4103/0974-1208.101014

9. Li SJ, Zhang YJ, Chai XS, Nie MF, Zhou YY, Chen JL, et al. Letrozole Ovulation Induction: An Effective Option in Endometrial Preparation for Frozen-Thawed Embryo Transfer. Arch Gynecol Obstetrics (2014) 289:68793. doi: 10.1007/s00404-013-3044-0

10. Chen D, Shen X, Fu Y, Ding C, Zhong Y, Zhou C. Pregnancy Outcomes Following Letrozole Use in Frozen-thawed Embryo Transfer Cycles: A Systematic Review and Meta-Analysis. Geburtshilfe und Frauenheilkunde (2020) 80:820-33. doi: 10.1055/a-1202-2059

11. Dellapasqua S, Colleoni M. Letrozole. Expert Opin Drug Metab Toxicol (2010) 6:251-9. doi: 10.1517/17425250903540246

12. Buzdar AU, Robertson JF, Eiermann W, Nabholtz JM. An Overview of the Pharmacology and Pharmacokinetics of the Newer Generation Aromatase Inhibitors Anastrozole, Letrozole, and Exemestane. Cancer (2002) 95:200616. doi: $10.1002 / \mathrm{cncr} .10908$

13. Sioufi A, Sandrenan N, Godbillon J, Trunet P, Czendlik C, Howald H, et al. Comparative Bioavailability of Letrozole Under Fed and Fasting Conditions in 12 Healthy Subjects After a $2.5 \mathrm{Mg}$ Single Oral Administration. Biopharm Drug Dispos (1997) 18:489-97. doi: 10.1002/(SICI)1099-081X(199708) 18:6<489::AID-BDD36>3.0.CO;2-P

14. Mitwally MF, Casper RF. Aromatase Inhibition Improves Ovarian Response to Follicle-Stimulating Hormone in Poor Responders. Fertil Steril (2002) 77:776-80. doi: 10.1016/S0015-0282(01)03280-0

15. Holzer H, Casper R, Tulandi T. A New Era in Ovulation Induction. Fertil Steril (2006) 85:277-84. doi: 10.1016/j.fertnstert.2005.05.078

16. Weil S, Vendola K, Zhou J, Bondy CA. Androgen and Follicle-Stimulating Hormone Interactions in Primate Ovarian Follicle Development. J Clin Endocrinol Metab (1999) 84:2951-6. doi: 10.1210/jcem.84.8.5929

17. Vendola KA, Zhou J, Adesanya OO, Weil SJ, Bondy CA. Androgens Stimulate Early Stages of Follicular Growth in the Primate Ovary. J Clin Invest (1998) 101:2622-9. doi: 10.1172/JCI2081

18. Weil SJ, Vendola K, Zhou J, Adesanya OO, Wang J, Okafor J, et al. Androgen Receptor Gene Expression in the Primate Ovary: Cellular Localization, Regulation, and Functional Correlations. J Clin Endocrinol Metab (1998) 83:2479-85. doi: 10.1210/jcem.83.7.4917

19. Vendola K, Zhou J, Wang J, Famuyiwa OA, Bievre M, Bondy CA. Androgens Promote Oocyte Insulin-Like Growth Factor I Expression and Initiation of Follicle Development in the Primate Ovary. Biol Reprod (1999) 61:353-7. doi: 10.1095/biolreprod61.2.353

20. Lønning P, Pfister C, Martoni A, Zamagni C. Pharmacokinetics of ThirdGeneration Aromatase Inhibitors. Semin Oncol (2003) 30:23-32. doi: 10.1016/ S0093-7754(03)00305-1

21. Yding Andersen C. Inhibin-B Secretion and FSH Isoform Distribution may Play an Integral Part of Follicular Selection in the Natural Menstrual Cycle. Mol Hum Reprod (2017) 23:16-24. doi: 10.1093/molehr/gaw070

22. Knight PG, Glister C. Local Roles of TGF-Beta Superfamily Members in the Control of Ovarian Follicle Development. Anim Reprod Sci (2003) 78:165-83. doi: 10.1016/S0378-4320(03)00089-7

23. Kranc W, Budna J, Kahan R, Chachuła A, Bryja A, Ciesiółka S, et al. Molecular Basis of Growth, Proliferation, and Differentiation of Mammalian Follicular Granulosa Cells. J Biol Regulators Homeostatic Agents (2017) 31:1-8.
24. Randall JM, Templeton A. Cervical Mucus Score and In Vitro Sperm Mucus Interaction in Spontaneous and Clomiphene Citrate Cycles. Fertil Steril (1991) 56:465-8. doi: 10.1016/S0015-0282(16)54541-5

25. Franks S, Adams J, Mason H, Polson D. Ovulatory Disorders in Women With Polycystic Ovary Syndrome. Clin Obstet Gynaecol (1985) 12:605-32. doi: 10.1016/S0306-3356(21)00138-2

26. Casper RF, Mitwally MF. A Historical Perspective of Aromatase Inhibitors for Ovulation Induction. Fertil Steril (2012) 98:1352-5. doi: 10.1016/j.fertnstert. 2012.10.008

27. Bao SH, Sheng SL, Peng YF, Lin QD. Effects of Letrozole and Clomiphene Citrate on the Expression of HOXA10 and Integrin Alpha V Beta 3 in Uterine Epithelium of Rats. Fertil Steril (2009) 91:244-8. doi: 10.1016/j.fertnstert. 2007.11.024

28. Crosignani PG, Bianchedi D, Riccaboni A, Vegetti W. Management of Anovulatory Infertility. Hum Reprod (1999) 14(Suppl 1):108-19. doi: 10.1093/humrep/14.suppl_1.108

29. Wang R, Kim BV, van Wely M, Johnson NP, Costello MF, Zhang H, et al. Treatment Strategies for Women With WHO Group II Anovulation: Systematic Review and Network Meta-Analysis. Bmj (2017) 356:j138. doi: 10.1136/bmj.j138

30. Hu S, Yu Q, Wang Y, Wang M, Xia W, Zhu C. Letrozole Versus Clomiphene Citrate in Polycystic Ovary Syndrome: A Meta-Analysis of Randomized Controlled Trials. Arch Gynecol Obstetrics (2018) 297:1081-8. doi: 10.1007/ s00404-018-4688-6

31. Roque M, Tostes AC, Valle M, Sampaio M, Geber S. Letrozole Versus Clomiphene Citrate in Polycystic Ovary Syndrome: Systematic Review and Meta-Analysis. Gynecol Endocrinol: Off I Int Soc Gynecol Endocrinol (2015) 31:917-21. doi: 10.3109/09513590.2015.1096337

32. Franik S, Eltrop SM, Kremer JA, Kiesel L, Farquhar C. Aromatase Inhibitors (Letrozole) for Subfertile Women With Polycystic Ovary Syndrome. Cochrane Database Systematic Rev (2018) 5:CD010287. doi: 10.1002/14651858. CD010287.pub3

33. Gadalla MA, Norman RJ, Tay CT, Hiam DS, Melder A, Pundir J, et al. Medical and Surgical Treatment of Reproductive Outcomes in Polycystic Ovary Syndrome: An Overview of Systematic Reviews. Int J Fertil Steril (2020) 13:257-70. doi: 10.22074/ijfs.2020.5608

34. Azim A, Oktay K. Letrozole for Ovulation Induction and Fertility Preservation by Embryo Cryopreservation in Young Women With Endometrial Carcinoma. Fertil Steril (2007) 88:657-64. doi: 10.1016/j.fertnstert. 2006.12.068

35. Yu Q, Hu S, Wang Y, Cheng G, Xia W, Zhu C. Letrozole Versus Laparoscopic Ovarian Drilling in Clomiphene Citrate-Resistant Women With Polycystic Ovary Syndrome: A Systematic Review and Meta-Analysis of Randomized Controlled Trials. Reprod Biol Endocrinol (2019) 17:17. doi: 10.1186/s12958019-0461-3

36. Casper RF, Mitwally MF. Use of the Aromatase Inhibitor Letrozole for Ovulation Induction in Women With Polycystic Ovarian Syndrome. Clin Obstetrics Gynecol (2011) 54:685-95. doi: 10.1097/GRF.0b013e3182353d0f

37. Abu Hashim H, El Rakhawy M, Abd Elaal I. Randomized Comparison of Superovulation With Letrozole vs. Clomiphene Citrate in an IUI Program for Women With Recently Surgically Treated Minimal to Mild Endometriosis. Acta Obstet Gynecol Scand (2012) 91:338-45. doi: 10.1111/j.1600-0412. 2011.01346.x

38. Zadehmodares S, Niyakan M, Sharafy SA, Yazdi MH, Jahed F. Comparison of Treatment Outcomes of Infertile Women by Clomiphene Citrate and Letrozole With Gonadotropins Underwent Intrauterine Insemination. Acta Med Iran (2012) 50:18-20. doi: 10.22074/ijfs.2020.5608

39. Bayar U, Tanriverdi HA, Barut A, Ayoğlu F, Ozcan O, Kaya E. Letrozole vs. Clomiphene Citrate in Patients With Ovulatory Infertility. Fertil Steril (2006) 85:1045-8. doi: 10.1016/j.fertnstert.2005.09.045

40. Mejia RB, Summers KM, Kresowik JD, Van Voorhis BJ. A Randomized Controlled Trial of Combination Letrozole and Clomiphene Citrate or Letrozole Alone for Ovulation Induction in Women With Polycystic Ovary Syndrome. Fertil Steril (2019) 111:571-578.e571. doi: 10.1016/j.fertnstert. 2018.11.030

41. Diamond MP, Mitwally M, Casper R, Ager J, Legro RS, Brzyski R, et al. Estimating Rates of Multiple Gestation Pregnancies: Sample Size Calculation From the Assessment of Multiple Intrauterine Gestations From Ovarian 
Stimulation (AMIGOS) Trial. Contemp Clin Trials (2011) 32:902-8. doi: 10.1016/j.cct.2011.07.009

42. Fouda UM, Sayed AM. Extended Letrozole Regimen Versus Clomiphene Citrate for Superovulation in Patients With Unexplained Infertility Undergoing Intrauterine Insemination: A Randomized Controlled Trial. Reprod Biol Endocrinol (2011) 9:84. doi: 10.1186/1477-7827-9-84

43. Eskew AM, Bedrick BS, Hardi A, Stoll CRT, Colditz GA, Tuuli MG, et al. Letrozole Compared With Clomiphene Citrate for Unexplained Infertility: A Systematic Review and Meta-Analysis. Obstetrics Gynecol (2019) 133:437-44. doi: 10.1097/AOG.0000000000003105

44. Quaas AM, Gavrizi SZ, Peck JD, Diamond MP, Legro RS, Robinson RD, et al. Endometrial Thickness After Ovarian Stimulation With Gonadotropin, Clomiphene, or Letrozole for Unexplained Infertility, and Association With Treatment Outcomes. Fertil Steril (2021) 115:213-20. doi: 10.1016/j.fertnstert. 2020.07.030

45. Tei C, Maruyama T, Kuji N, Miyazaki T, Mikami M, Yoshimura Y. Reduced Expression of Alphavbeta3 Integrin in the Endometrium of Unexplained Infertility Patients With Recurrent IVF-ET Failures: Improvement by Danazol Treatment. J Assist Reprod Genet (2003) 20:13-20. doi: 10.1023/A:1021254620888

46. Ganesh A, Chauhan N, Das S, Chakravarty B, Chaudhury K. Endometrial Receptivity Markers in Infertile Women Stimulated With Letrozole Compared With Clomiphene Citrate and Natural Cycles. Syst Biol Reprod Med (2014) 60:105-11. doi: 10.3109/19396368.2013.862316

47. Garcia-Velasco JA, Moreno L, Pacheco A, Guillen A, Duque L, Requena A, et al. The Aromatase Inhibitor Letrozole Increases the Concentration of Intraovarian Androgens and Improves In Vitro Fertilization Outcome in Low Responder Patients: A Pilot Study. Fertil Steril (2005) 84:82-7. doi: 10.1016/j.fertnstert.2005.01.117

48. Lazer T, Dar S, Shlush E, Al Kudmani BS, Quach K, Sojecki A, et al. Comparison of IVF Outcomes Between Minimal Stimulation and HighDose Stimulation for Patients With Poor Ovarian Reserve. Int J Reprod Med (2014) 2014:581451. doi: 10.1155/2014/581451

49. Haas J, Casper RF. In Vitro Fertilization Treatments With the Use of Clomiphene Citrate or Letrozole. Fertil Steril (2017) 108:568-71. doi: 10.1016/ j.fertnstert.2017.08.017

50. Shapira M, Orvieto R, Lebovitz O, Nahum R, Aizer A, Segev-Zahav A, et al. Does Daily Co Administration of Gonadotropins and Letrozole During the Ovarian Stimulation Improve IVF Outcome for Poor and Sub Optimal Responders? J Ovarian Res (2020) 13:66. doi: 10.1186/s13048-020-00666-z

51. D’Amato G, Caringella AM, Stanziano A, Cantatore C, Palini S, Caroppo E. Mild Ovarian Stimulation With Letrozole Plus Fixed Dose Human Menopausal Gonadotropin Prior to IVF/ICSI for Infertile non-Obese Women With Polycystic Ovarian Syndrome Being Pre-Treated With Metformin: A Pilot Study. Reprod Biol Endocrinol (2018) 16:89. doi: 10.1186/s12958-018-0405-3

52. Ecemis T, Tasci Y, Caglar GS. Controlled Ovarian Hyperstimulation With Sequential Letrozole Co-Treatment in Normo/High Responders. Gynecol Endocrinol: Off J Int Soc Gynecol Endocrinol (2016) 32:206-9. doi: 10.3109/ 09513590.2015 .1110133

53. Miller PB, Parnell BA, Bushnell G, Tallman N, Forstein DA, Higdon HL3rd, et al. Endometrial Receptivity Defects During IVF Cycles With and Without Letrozole. Hum Reprod (2012) 27:881-8. doi: 10.1093/humrep/der452

54. Rose BI. The Potential of Letrozole Use for Priming In Vitro Maturation Cycles. Facts Views Vision ObGyn (2014) 6:150-5.

55. Kamath MS, Maheshwari A, Bhattacharya S, Lor KY, Gibreel A. Oral Medications Including Clomiphene Citrate or Aromatase Inhibitors With Gonadotropins for Controlled Ovarian Stimulation in Women Undergoing In Vitro Fertilisation. Cochrane Database Systematic Rev (2017) 11:Cd008528. doi: 10.1002/14651858.CD008528.pub3

56. Chuderland D, Ben-Ami I, Kaplan-Kraicer R, Grossman H, Ron-El R, Shalgi R. The Role of Pigment Epithelium-Derived Factor in the Pathophysiology and Treatment of Ovarian Hyperstimulation Syndrome in Mice. J Clin Endocrinol Metab (2013) 98:E258-66. doi: 10.1210/jc.2012-3037

57. Sahin N, Apaydin N, Toz E, Sivrikoz ON, Genc M, Turan GA, et al. Comparison of the Effects of Letrozole and Cabergoline on Vascular Permeability, Ovarian Diameter, Ovarian Tissue VEGF Levels, and Blood PEDF Levels, in a Rat Model of Ovarian Hyperstimulation Syndrome. Arch Gynecol Obstetrics (2016) 293:1101-6. doi: 10.1007/s00404-015-3987-4
58. Tshzmachyan R, Hambartsoumian E. The Role of Letrozole (LE) in Controlled Ovarian Stimulation (COS) in Patients at High Risk to Develop Ovarian Hyper Stimulation Syndrome (OHSS). A Prospective Randomized Controlled Pilot Study. J Gynecol Obstet Hum Reprod (2019) 49:101643. doi: 10.1016/j.jogoh.2019.101643

59. Wang Y-Q, Luo J, Xu W-M, Xie Q-Z, Yan W-J, Wu G-X, et al. Can Steroidal Ovarian Suppression During the Luteal Phase After Oocyte Retrieval Reduce the Risk of Severe OHSS? J Ovarian Res (2015) 8:63. doi: 10.1186/s13048-0150190-y

60. Zhang J, Liu H, Wang Y, Mao X, Chen Q, Fan Y, et al. Letrozole Use During Frozen Embryo Transfer Cycles in Women With Polycystic Ovary Syndrome. Fertil Steril (2019) 112:371-7. doi: 10.1016/j.fertnstert.2019.04.014

61. Tatsumi T, Jwa SC, Kuwahara A, Irahara M, Kubota T, Saito H. Pregnancy and Neonatal Outcomes Following Letrozole Use in Frozen-Thawed Single Embryo Transfer Cycles. Hum Reprod (2017) 32:1244-8. doi: 10.1093/ humrep/dex066

62. Mackens S, Santos-Ribeiro S, van de Vijver A, Racca A, Van Landuyt L, Tournaye H, et al. Frozen Embryo Transfer: A Review on the Optimal Endometrial Preparation and Timing. Hum Reprod (2017) 32:2234-42. doi: 10.1093/humrep/dex285

63. Yarali H, Polat M, Mumusoglu S, Yarali I, Bozdag G. Preparation of Endometrium for Frozen Embryo Replacement Cycles: A Systematic Review and Meta-Analysis. J Assisted Reprod Genet (2016) 33:1287-304. doi: 10.1007/s10815-016-0787-0

64. Glujovsky D, Pesce R, Sueldo C, Quinteiro Retamar AM, Hart RJ, Ciapponi A. Endometrial Preparation for Women Undergoing Embryo Transfer With Frozen Embryos or Embryos Derived From Donor Oocytes. Cochrane Database Systematic Rev (2020) 10:Cd006359. doi: 10.1002/14651858. CD006359.pub3

65. Abu Hashim H. Potential Role of Aromatase Inhibitors in the Treatment of Endometriosis. Int J Women's Health (2014) 6:671-80. doi: 10.2147/IJWH.S34684

66. Alborzi S, Hamedi B, Omidvar A, Dehbashi S, Alborzi S, Alborzi M. A Comparison of the Effect of Short-Term Aromatase Inhibitor (Letrozole) and GnRH Agonist (Triptorelin) Versus Case Control on Pregnancy Rate and Symptom and Sign Recurrence After Laparoscopic Treatment of Endometriosis. Arch Gynecol Obstetrics (2011) 284:105-10. doi: 10.1007/ s00404-010-1599-6

67. Chen C, Sun S, Yuan JP, Wang YH, Cao TZ, Zheng HM, et al. Characteristics of Breast Cancer in Central China, Literature Review and Comparison With USA. Breast (2016) 30:208-13. doi: 10.1016/j.breast.2016.01.004

68. Lambertini M, Peccatori FA, Demeestere I, Amant F, Wyns C, Stukenborg JB, et al. Fertility Preservation and Post-Treatment Pregnancies in Post-Pubertal Cancer Patients: ESMO Clinical Practice Guidelines( $\dagger)$. Ann Oncology: Off $J$ Eur Soc Med Oncol (2020) 31:1664-78. doi: 10.1016/j.annonc.2020.09.006

69. Pereira N, Hancock K, Cordeiro CN, Lekovich JP, Schattman GL, Rosenwaks Z. Comparison of Ovarian Stimulation Response in Patients With Breast Cancer Undergoing Ovarian Stimulation With Letrozole and Gonadotropins to Patients Undergoing Ovarian Stimulation With Gonadotropins Alone for Elective Cryopreservation of Oocytesdagger. Gynecol Endocrinol: Off J Int Soc Gynecol Endocrinol (2016) 32:823-6. doi: 10.1080/09513590.2016.1177013

70. Bonardi B, Massarotti C, Bruzzone M, Goldrat O, Mangili G, Anserini P, et al. Efficacy and Safety of Controlled Ovarian Stimulation With or Without Letrozole Co-administration for Fertility Preservation: A Systematic Review and Meta-Analysis. Front Oncol (2020) 10:574669. doi: 10.3389/fonc. 2020.574669

71. Goldrat O, Gervy C, Englert Y, Delbaere A, Demeestere I. Progesterone Levels in Letrozole Associated Controlled Ovarian Stimulation for Fertility Preservation in Breast Cancer Patients. Hum Reprod (2015) 30:2184-9. doi: 10.1093/humrep/dev155

72. Quinn MM, Cakmak H, Letourneau JM, Cedars MI, Rosen MP. Response to Ovarian Stimulation is Not Impacted by a Breast Cancer Diagnosis. Hum Reprod (2017) 32:568-74. doi: 10.1093/humrep/dew355

73. Oktay K, Turan V, Bedoschi G, Pacheco Fernanda S, Moy F. Fertility Preservation Success Subsequent to Concurrent Aromatase Inhibitor Treatment and Ovarian Stimulation in Women With Breast Cancer. J Clin Oncol (2015) 33:2424-9. doi: 10.1200/JCO.2014.59.3723

74. Kawahara T, Okamoto N, Takae S, Kashiwagi M, Nakajima M, Uekawa A, et al. Aromatase Inhibitor Use During Ovarian Stimulation Suppresses 
Growth of Uterine Endometrial Cancer in Xenograft Mouse Model. Hum Reprod (2018) 33:303-10. doi: 10.1093/humrep/dex368

75. Zhang Z, Huang H, Feng F, Wang J, Cheng N. A Pilot Study of Gonadotropin-Releasing Hormone Agonist Combined With Aromatase Inhibitor as Fertility-Sparing Treatment in Obese Patients With Endometrial Cancer. J Gynecologic Oncol (2019) 30:e61. doi: 10.3802/ jgo.2019.30.e61

76. Mangili G, Somigliana E, Giorgione V, Martinelli F, Filippi F, Petrella MC, et al. Fertility Preservation in Women With Borderline Ovarian Tumours. Cancer Treat Rev (2016) 49:13-24. doi: 10.1016/j.ctrv.2016.06.010

77. Tulandi T, Martin J, Al-Fadhli R, Kabli N, Forman R, Hitkari J, et al. Congenital Malformations Among 911 Newborns Conceived After Infertility Treatment With Letrozole or Clomiphene Citrate. Fertil Steril (2006) 85:1761-5. doi: 10.1016/j.fertnstert.2006.03.014

78. Tatsumi T, Jwa SC, Kuwahara A, Irahara M, Kubota T, Saito H. No Increased Risk of Major Congenital Anomalies or Adverse Pregnancy or Neonatal Outcomes Following Letrozole Use in Assisted Reproductive Technology. Hum Reprod (2017) 32:125-32. doi: 10.1093/humrep/dew280

79. Pritts EA. Letrozole for Ovulation Induction and Controlled Ovarian Hyperstimulation. Curr Opin Obstet Gynecol (2010) 22:289-94. doi: 10.1097/GCO.0b013e32833beebf

80. Hoffman JI. Incidence of Congenital Heart Disease: I. Postnatal Incidence. Pediatr Cardiol (1995) 16:103-13. doi: 10.1007/BF00801907

81. Roselli CE, Klosterman S, Resko JA. Anatomic Relationships Between Aromatase and Androgen Receptor mRNA Expression in the Hypothalamus and Amygdala of Adult Male Cynomolgus Monkeys. J Comp Neurol (2001) 439:208-23. doi: 10.1002/cne.1343

82. Hurria A, Patel SK, Mortimer J, Luu T, Somlo G, Katheria V, et al. The Effect of Aromatase Inhibition on the Cognitive Function of Older Patients With Breast Cancer. Clin Breast Cancer (2014) 14:132-40. doi: 10.1016/j.clbc.2013.10.010

83. Bender CM, Merriman JD, Gentry AL, Ahrendt GM, Berga SL, Brufsky AM, et al. Patterns of Change in Cognitive Function With Anastrozole Therapy. Cancer (2015) 121:2627-36. doi: 10.1002/cncr.29393
84. Karatas F, Akin S, Babacan T, Sever AR, Altundag K. Can Aromatase Inhibitors Cause Forgetfulness in Women With Breast Cancer? J BUON: Off J Balkan Union Oncol (2015) 20:935.

85. Rune GM, Lohse C, Prange-Kiel J, Fester L, Frotscher M. Synaptic Plasticity in the Hippocampus: Effects of Estrogen From the Gonads or Hippocampus? Neurochemical Res (2006) 31:145-55. doi: 10.1007/s11064005-9004-8

86. Vierk R, Bayer J, Freitag S, Muhia M, Kutsche K, Wolbers T, et al. StructureFunction-Behavior Relationship in Estrogen-Induced Synaptic Plasticity. Hormones Behav (2015) 74:139-48. doi: 10.1016/j.yhbeh.2015.05.008

87. Bayer J, Rune G, Schultz H, Tobia MJ, Mebes I, Katzler O, et al. The Effect of Estrogen Synthesis Inhibition on Hippocampal Memory. Psychoneuroendocrinology (2015) 56:213-25. doi: 10.1016/j.psyneuen.2015.03.011

88. Jenkins V, Shilling V, Fallowfield L, Howell A, Hutton S. Does Hormone Therapy for the Treatment of Breast Cancer Have a Detrimental Effect on Memory and Cognition? A Pilot Study. Psycho-oncology (2004) 13:61-6. doi: 10.1002/pon.709

89. Rocha-Cadman X, Massie MJ, Du Hamel K. Aromatase Inhibitors and Mood Disturbances. Palliative Supportive Care (2012) 10:225-7. doi: 10.1017/ S1478951512000636

90. Palomba S. Aromatase Inhibitors for Ovulation Induction. J Clin Endocrinol Metab (2015) 100:1742-7. doi: 10.1210/jc.2014-4235

Conflict of Interest: The authors declare that the research was conducted in the absence of any commercial or financial relationships that could be construed as a potential conflict of interest.

Copyright $\odot 2021$ Yang, Cui, Sun and Hao. This is an open-access article distributed under the terms of the Creative Commons Attribution License (CC BY). The use, distribution or reproduction in other forums is permitted, provided the original author(s) and the copyright owner(s) are credited and that the original publication in this journal is cited, in accordance with accepted academic practice. No use, distribution or reproduction is permitted which does not comply with these terms. 